\title{
The Effects of Climate and Anthropogenic Activity on Hydrologic Features in Yanhe River
}

\author{
Yang Cheng, ${ }^{1}$ Hongming $\mathrm{He}^{2}$ Nannan Cheng, ${ }^{2,3}$ and Wenming $\mathrm{He}^{4}$ \\ ${ }^{1}$ Department of Civil and Environmental Engineering, Syracuse University, Syracuse, NY 13210, USA \\ ${ }^{2}$ State Key Laboratory of Soil Erosion and Dryland Farming on Loess Plateau, Northwest of Agriculture \& Forestry \\ University and Institute of Soil and Water Conservation, Chinese Academy of Sciences \& Ministry of Water Resources, \\ Yangling, Shaanxi 712100, China \\ ${ }^{3}$ Graduate University, Chinese Academy of Sciences, Beijing 712100, China \\ ${ }^{4}$ School of Chemistry and Environment, Jiaying University, Guangdong, China \\ Correspondence should be addressed to Hongming He; hongming.he@yahoo.com
}

Received 30 April 2015; Revised 2 August 2015; Accepted 6 August 2015

Academic Editor: Olga Zolina

Copyright (c) 2016 Yang Cheng et al. This is an open access article distributed under the Creative Commons Attribution License, which permits unrestricted use, distribution, and reproduction in any medium, provided the original work is properly cited.

\begin{abstract}
This paper aims to analyze the effects of precipitation and anthropogenic activity on hydrologic features in Yanhe River so as to provide support for regional water management and evaluation of water and soil conservation measures. Thiessen Polygon was created to calculate mean values of watershed, and Mann-Kendall statistic test and Sen's slop estimator test were adapted to analyze variation trend and interaction between precipitation, runoff, and sediment discharge. When 1961 1970 was set as reference period (ignoring human effects), the double mass curve quantified the effects of precipitation and anthropogenic activity on runoff and sediment discharge in Yanhe River during 1961 2008. The result showed that the monthly distribution of precipitation, runoff, and sediment discharge was extremely uneven. $78.1 \%$ of precipitation, $64.1 \%$ of runoff, and $98.6 \%$ of sediment discharge occurred in the flood season. Precipitation, runoff, and sediment discharge performed significant downward trends during 1961-2008. Therein, anthropogenic factors contributed $66.7 \%$ and $51.1 \%$ to sediment discharge reduction during 1971-1994 and 1995-2008, respectively. They contributed $103.8 \%$ and $82.9 \%$ to runoff reduction during these two periods, respectively.
\end{abstract}

\section{Introduction}

Precipitation variation and anthropogenic activities are major effects on hydrology and soil erosion. Global warming accelerates regional water cycle, changes precipitation intensity and frequency, and therefore affects hydrologic process [1]. The responses of basin hydrology to climate are different over the world. Goode et al. [2] expected sediment yields to increase in response to changing climate in northern Rocky Mountains, USA. Mouri et al. [3] estimated that suspended sediment yield would increase from $8 \%$ to $24 \%$ per year for the MRI-GCM in response to future climate changing. However, Liu et al. [4] found that precipitation in most weather stations of China have significant reducing trend, and Wang et al. [5] showed that decrease of precipitation induced temporal and spatial decrease of streamflow. Meanwhile, anthropogenic activities for transformation of underlying surface such as land use change, water conservancy construction, and water and soil conservation measures have both significant effects on water cycle and runoff process. Moreover, human activities have altered the spatial-temporal distribution of water resources [6-8]. Hence, water balance becomes an urgent problem in Loess Plateau under both effects of precipitation variation and human activities. Currently, there are several methods such as watershed comparison, hydrologic modeling, and analysis of time series to quantify hydrologic effects caused by environmental change. Therein, analysis of time series has widespread use in evaluation of environment effect due to its simple use and operability [9]. Through researching streamflow of the mainstream of Yellow River during 1956-2000, Liu and Zhang [10] concluded that effect of precipitation on runoff reduction of upper reaches of the Yellow River accounted for $75 \%$, whereas human activities accounted for $25 \%$; however, precipitation accounted for $43 \%$ 
and human activities accounted for 57\% in middle reaches of the Yellow River. Li [9] found that precipitation and human activities contribute $24 \%$ and $76 \%$, respectively, to runoff reduction in Hei He watershed (secondary tributary) during 1972 to 2000. These researches show that runoff has various responses to precipitation and anthropogenic activities by different spatial scales. The considerable attention has been paid to studying the impacts of climate variations and human-induced factors on water resources within a watershed scale [11-17].

Loess Plateau is a region of severest water and soil loss in China. YanHe River is first tributary of Yellow River and it has typical landform of hilly-gully in north part of Loess Plateau. Variation of runoff and sediment discharge to some extent represents the trend of runoff and sediment discharge of the middle reaches of Yellow River because heavy erosion occurred in Yanhe watershed. Climate change impacts on hydrogeomorphological processes are dominated by short and severe rainstorms which accelerated erosion [18]. He et al. [19] also indicated that concurrent flooding in multiple tributary rivers accounted for $67.5 \%$ of the total flooding in the middle Yellow River. Numerous studies indicated that the sediment load in many large rivers has been reduced significantly by human activities such as construction of dams, water divisions, and other water stores [20-23]. In the middle of 1980s, sediments of hilly-gully region of Loess Plateau have been significantly decreased due to vegetation practices and engineering measures [24]. Particularly, sediments reduced $81.8 \%$ after 2000 compared to past 60 years in the middle reaches of Yellow River [25].

The government had conducted a series of soil and conservation measures in Yanhe River since 1960s. Major measures included vegetation planting, silt dam and reservoir built, and terraced field construction. Moreover, government implemented massive projects of Grain for Green which returned farmland to forest or grassland after 1997. Many researches for effects of water and sediment by management measures concluded that the benefits of these measures significantly appeared around $1971[14,26]$ and the project of Grain for Green in the late 20th century had significantly reduced runoff and sediment discharge [27-29]. Combined with previous studies in small scale watershed such as land use/cover change and meteorological events, it is helpful to quantify the effects of anthropogenic and meteorological factors on runoff and sediment discharge in Yanhe River. The study will support not only water and soil conservation but also sustainable water resource use of Yanhe River.

\section{Study Area}

Yanhe River is the first-grade tributary flowing of Yellow River and stems from the south of Bai Yu Mountain. It has overall length of $284.4 \mathrm{~km}$ and the total area of $7591 \mathrm{~km}^{2}$. The river flows through northwest to southeast via Zhi Dan, An Sai, Yan An, and Yan Chang counties. The watershed $\left(36^{\circ} 21^{\prime}-37^{\circ} 19^{\prime} \mathrm{N}, 108^{\circ} 38^{\prime}-110^{\circ} 29^{\prime} \mathrm{E}\right)$ has several tributaries such as Xi Chuan, Pan Long Chuan, and Nan Chuan, and the average watercourse gradient, average slope, and average elevation are $3.29 \%, 17^{\circ}$, and $1218 \mathrm{~m}$, respectively [30] (this reference is Chinese version with English abstract).

The watershed is located in temperate continental semiarid monsoon area. The weather is arid, windy, and varying in temperature in spring. In summer, the weather is tepid but has intensive runoff. Compared to the weather of winter which is cold and dry and lasts longer, it is rainy with rapid temperature decreasing in autumn. Interannual precipitation has significant change, and annual mean precipitation is around $500 \mathrm{~mm}$. Particularly, $60 \%$ of annual precipitation is coming from July to September and most of it is rainstorm. Average wind speed in watershed is between 1.3 and $3 \mathrm{~m} / \mathrm{s}$ [30]. Southeaster dominated in summer and northwester prevails in winter. Strong gale of cold wave occurs during spring and winter and is accompanied with rapid temperature change. Average temperature in watershed is $9.4^{\circ} \mathrm{C}$ and increasing from northwest to southeast. Interannual temperature has substantial change that average daily difference of temperature reaches almost $13^{\circ} \mathrm{C}$. Vegetation is distributed in the order of forest, forest steppe, and grass from southeast to northwest [31]. Main soil type is loessal soil; the others are red clay and Heilu soil. Loessal soil is predominately cultivated soil because it is fertile and holding more than $85 \%$ area in the watershed [31]. Silt is major constitution of pore-size distribution in loessal soil so that its persistence for erosion is poor and it is easy to disperse and carry. Loessal soils are widespread on the sloping fields. Red soil contains higher content of clay but it is less fertile, is hard for tillage, and has lower permeability. Red soils are widespread on the bottom of trench or slop.

\section{Material and Methods}

3.1. Data Source. The precipitation data used in the paper come from county-level station of China, including Yan An, An Sai, Zhi Dan, and Yan Chang weather stations and Gan Guyi during 1961 to 2008 (Figure 1). Time series of data processing are defined as flood season (June to September), spring (March to May), summer (June to August), fall (September to November), and winter (December to February). In this study, climate, hydrological, and sediment datasets are used to investigate effects of climate and anthropogenic activity on hydrologic features in Yanhe River in the past 60 years. These include climatic, hydrologic, and topographic datasets (Figure 1). The meteorological datasets of 4 observation stations, which include daily, monthly, and annual precipitation during 1961-2008, were used to illustrate climate change situations in Yanhe River. These datasets were provided by National Meteorological Information Center (NMIC), China Meteorological Administration (CMA). The hydrological datasets of gauge station were used to carry out hydrometeorological analysis and soil erosion as well. These datasets include daily stream-flow and sediment discharge from 1961 to 2008. These datasets were provided by Ecological Environment Database of the Loess Plateau, Chinese Academy of Sciences and Ministry of Water Resources (CAS\&MWR). Topographic parameters, such as gully density, slope, aspect, relief, and river network, were extracted 


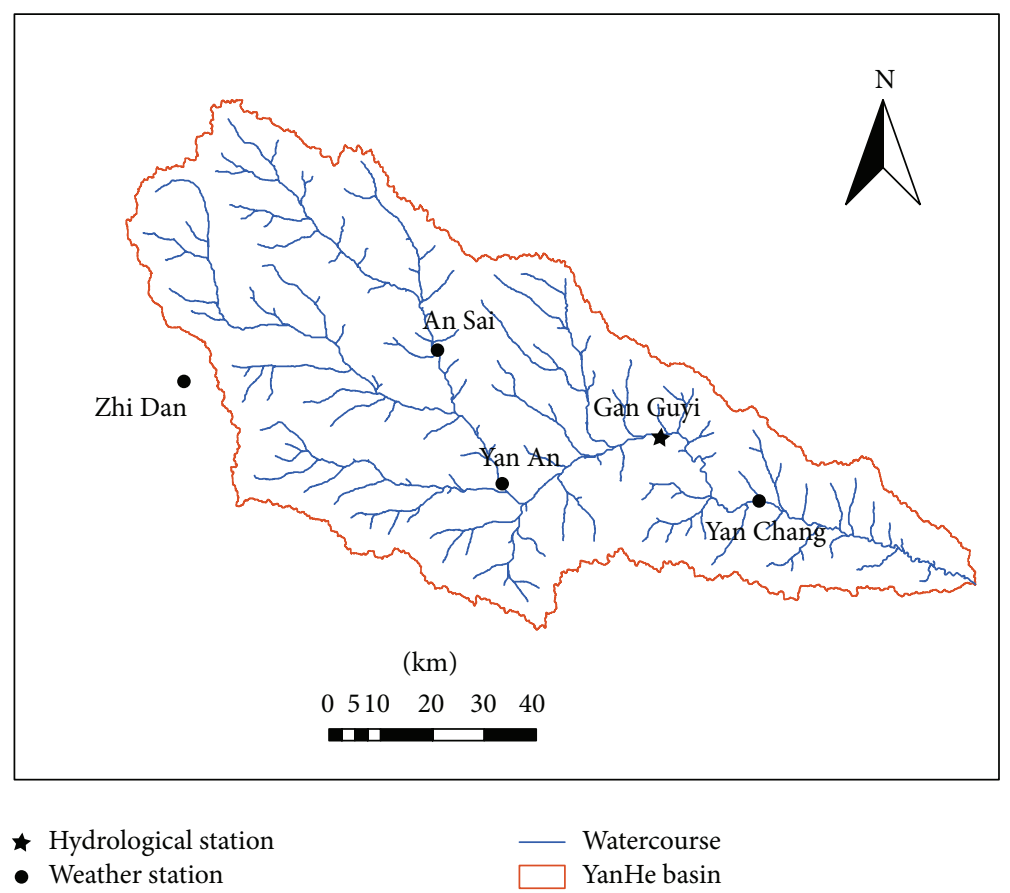

FIgURE 1: Geographic location of the Yanhe River and its meteorological and hydrological stations.

from 30 meters resolution DEM which was downloaded from International Scientific \& Technical Data Mirror Site, Computer Network Information Center of Chinese Academy of Sciences.

3.2. Methods. Analysis of precipitation and runoff was based on four observed stations (Figure 1). When it comes to the whole river basin situation, the total runoff and sediment correspond to the total precipitation of the Yanhe River, while in correlation analysis of precipitation, runoff, and sediments at subbasin scales, specific observation datasets were used. Using dataset of a specific gauge station or an average of the whole river basin depends on specific task in data analysis. While the precipitation was never uniformly falling over the entire area of the subbasin but varies in intensity and duration from place to place, Thiessen Polygon method was more suitable than arithmetic mean method, which assigned at each weather station in proportion to the watershed area that is the closest to that station, so as to attain mean rainfall by calculating weighted average. For missing data of precipitation in An Sai weather station in 1962, 1968, and 1969, we interpolated the missing historic precipitation data by using the nearest weather station (Zhao An) which has less than $15 \mathrm{~km}$ away from An Sai station. Therefore, effective precipitation data of 48 years in each weather station were ensured.

Mann-Kendall statistical method [32] is applied for trend analysis. In the 2 -sided trend test, for given significant $\alpha$, if $|Z|$ is smaller than $Z_{1-\alpha / 2}$, null hypothesis is accepted. If $|Z|$ is greater than $Z_{1-\alpha / 2}$, null hypothesis is not accepted; in other words, time series data has significant trend of growth or decrease. The trend would be increased when $Z$ becomes positive and vice versa. The values of $1.28,1.64$, and 2.32 represent confidence of $90 \%, 95 \%$, and $99 \%$, respectively.
When Mann-Kendall is used for detecting changing point, test statistic is different with $Z$; define statistic through

$$
S_{k}=\sum_{i=1}^{k} \sum_{j=1}^{i} \alpha_{i j} \quad(k=2,3,4, \ldots, n),
$$

where

$$
\alpha_{i j}=\left\{\begin{array}{ll}
1, & x_{i}>x_{j} \\
0, & x_{i} \leq x_{j}
\end{array} \quad 1 \leq j \leq i\right.
$$

Then,

$$
\mathrm{UF}_{k}=\frac{\left|S_{k}-E\left(S_{k}\right)\right|}{\sqrt{\operatorname{Var}\left(S_{k}\right)}} \quad(k=1,2, \ldots, n),
$$

where

$$
\begin{aligned}
E\left(S_{k}\right) & =\frac{k(k-1)}{4} ; \\
\operatorname{Var}\left(S_{k}\right) & =\frac{k(k+1)(2 k+5)}{72} .
\end{aligned}
$$

$\mathrm{UF}_{i}$ is standard normal distribution. For given confidence $\alpha$, if $\left|U_{i}\right|>U_{\alpha / 2}$, the sequence has significant trend. To calculate $\mathrm{UB}_{k}$ using the above equation, inverse time sequence, and make $\mathrm{UB}_{k}=-\mathrm{UF}_{k}(k=n, n-1 \cdots 2)$ and $\mathrm{UB}_{1}=0$, if the curve of $\mathrm{UF}_{k}$ and $\mathrm{UB}_{k}$ has intersection and the point of intersection is located within the critical lines, the corresponding time of intersection point is the time for abrupt change.

Sen [33] developed the nonparametric procedure to estimate the slope of trend in the sample of $N$ pairs of data:

$$
Q_{i}=\frac{x_{j}-x_{k}}{j-k} \quad(i=1, \ldots, N)
$$



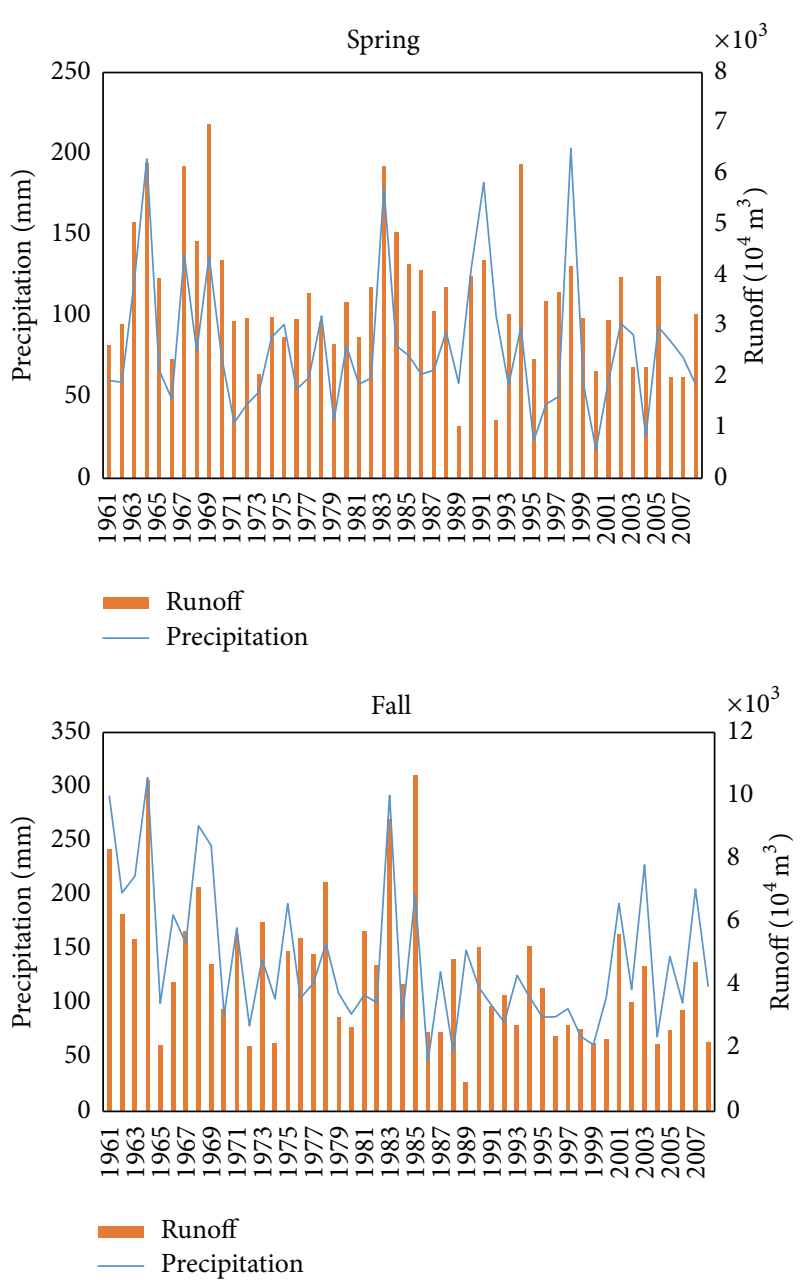
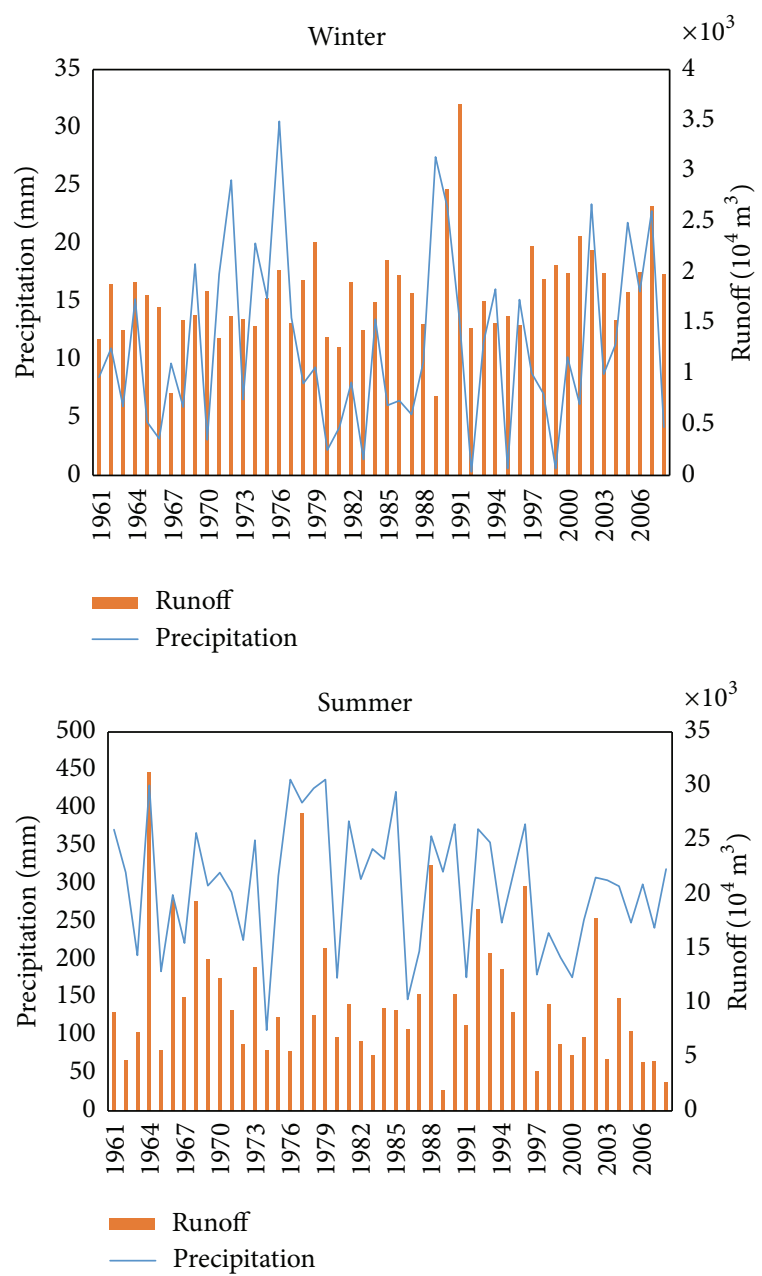

FIgURE 2: Seasonal distribution of runoff and precipitation in the Yanhe River.

where $x_{j}$ and $x_{k}$ are the values at times $j$ and $k(j>k)$, respectively. The $N$ values of $Q_{i}$ are ranked from smallest to largest and the median value of $Q_{i}$ is slope of this datum [34]. $Q_{\text {med }}$ is computed as

$$
Q_{\text {med }}= \begin{cases}Q_{(n+1) / 2}, & \text { if } n \text { is odd, } \\ \frac{Q_{n / 2}+Q_{(n+2) / 2}}{2}, & \text { if } n \text { is even. }\end{cases}
$$

$Q_{\text {med }}$ does not contain zero and its values indicate the steepness of trend.

The double mass curve is a method to test consistency and variation between two parameters. The double mass curve is a relation line of two variables in the same period drawn in rectangular coordinate system. It is used to test consistency of meteorological elements, interpolate missing values, or data rectification $[35,36]$.

\section{Result and Discussion}

4.1. Changing Pattern of Precipitation, Runoff, and Sediment Discharge in Yanhe River from 1961 to 2008. The seasonal distribution of precipitation and runoff in Yanhe River is extraordinarily uneven (Figure 2). The most of precipitation and runoff occurred in the summer and fall and accounted for $82.5 \%$ and $73.8 \%$ of annual amount, respectively (Table 1). The precipitation and runoff in summer accounted for $56.2 \%$ and $51.7 \%$, and variable coefficients are 0.28 and 0.61 , respectively. The precipitation and runoff in fall accounted for $26.3 \%$ and 21.1, respectively, and variable coefficients of them are 0.48 and 0.51 . Compared with the proportion of precipitation and runoff in summer and fall, however, the proportion of precipitation in other seasons is lower but variable coefficients are higher, and the variable coefficients of runoff in winter and spring are lower which means the runoff of Yanhe River in winter and spring is relatively stable and less affected by precipitation. Base flow from upstream is major contribution to runoff of Yanhe River. In other words, the precipitation is major recharge source of runoff in Yanhe River in summer and fall.

Results of applying trend analysis by Mann-Kendall and Sen's slope estimator statistical tests for seasonal precipitation and runoff over period of 1961-2008 are presented in Table 2. As shown, the precipitation of spring, summer, and fall performed subtly increasing trend in seasonal time scale. Thereinto, the decreasing trend in fall was detected at $95 \%$ 
TABLE 1: The characteristics of precipitation and runoff at the outlet (river mouth) in Yanhe River.

\begin{tabular}{|c|c|c|c|c|c|c|}
\hline & & Annual & Spring & Summer & Fall & Winter \\
\hline \multirow{5}{*}{ Precipitation } & Maximum $(\mathrm{mm})$ & 954 & 204.6 & 440 & 308.7 & 30.8 \\
\hline & Minimum (mm) & 264.6 & 17.7 & 107.3 & 45.6 & 0.3 \\
\hline & Average (mm) & 531.5 & 81.8 & 299.1 & 139.4 & 11.3 \\
\hline & Percentage (\%) & - & 15.4 & 56.2 & 26.3 & 2.1 \\
\hline & Variable coefficient & 0.26 & 0.52 & 0.28 & 0.48 & 0.68 \\
\hline \multirow{5}{*}{ Runoff } & Maximum $\left(10^{4} \mathrm{~m}^{3}\right)$ & 50206.4 & 7040.3 & 31520.2 & 10650.6 & 3692 \\
\hline & Minimum $\left(10^{4} \mathrm{~m}^{3}\right)$ & 4609.1 & 1036.3 & 1859 & 926.3 & 787.4 \\
\hline & Average $\left(10^{4} \mathrm{~m}^{3}\right)$ & 20291 & 3566.5 & 10500.4 & 4283 & 1808.5 \\
\hline & Percentage (\%) & - & 17.6 & 51.7 & 21.1 & 8.9 \\
\hline & Variable coefficient & 0.39 & 0.37 & 0.61 & 0.52 & 0.27 \\
\hline
\end{tabular}

TABle 2: The results of Mann-Kendall and Sen's slope for precipitation, runoff, and sediment discharge.

\begin{tabular}{|c|c|c|c|c|c|c|}
\hline & \multirow{2}{*}{ Test } & \multicolumn{5}{|c|}{ Trend } \\
\hline & & Annual & Spring & Summer & Fall & Winter \\
\hline \multirow{2}{*}{ Precipitation } & $Z_{s}$ & -2.40 & -0.46 & -1.08 & -2.46 & 0.46 \\
\hline & $Q_{\text {med }}$ & -2.65 & -0.12 & -1.06 & -1.71 & 0.03 \\
\hline \multirow{2}{*}{ Runoff } & $Z_{s}$ & -2.37 & -1.63 & -1.80 & -3.05 & 2.85 \\
\hline & $Q_{\text {med }}$ & -173.03 & -23.33 & -87.53 & -62.95 & 10.68 \\
\hline \multirow{2}{*}{ Sediment discharge } & $Z_{s}$ & -2.39 & - & - & - & - \\
\hline & $Q_{\text {med }}$ & -57.24 & - & - & - & - \\
\hline
\end{tabular}

confidence level. The precipitation in winter infinitesimal increased $0.03 \mathrm{~mm}$ per year. The runoff from Gan Guyi hydrological station showed that the trends were downward except in winter, the runoff in winter significantly increased (2.85), and there was 0.11 million cubic meters increased per year. However, the runoff in spring, summer, and fall had negative trends in about $0.23,0.87$, and 0.62 million $\mathrm{m}^{3}$ per year decrease, respectively. Thereinto, runoff in summer had negative trend $(-1.8)$ at $95 \%$ confidence level, and the runoff in fall had negative trends $(-3.05)$ at $99 \%$ confidence level. The reason why runoff in these two seasons (summer and fall) had downward trends was probably because of two aspects: the decreasing of precipitation in these two seasons and the other might be related to human activity such as land cover change and the surged demand of water caused by popularity growth.

The trends of annual precipitation and runoff change were shown in Figure 3. Generally, the variation of precipitation corresponds to runoff changes. The precipitation had decreased between the late 1960s and middle of 1970s. During late 1970s and middle of 1980s, the precipitation had dramatic fluctuation. Its variation became gentle after 1990s. The trend line of precipitation in Figure 3 showed that annual average precipitation was decreasing and annual average decline factor is $-3.1 \mathrm{~mm} / \mathrm{a}$. In Sen's slope estimator statistic test, the trend of precipitation was detected at rate of $-2.65 \mathrm{~mm} / \mathrm{a}$. Through nonparametric Mann-Kendall test, $\mathrm{M}-\mathrm{K}$ rank correlation coefficient of precipitation $(-2.40)$ has 99\% confidence which showed that precipitation has significantly reduced trend along with time sequence. The trend of runoff decreased as well and annual average reduction is 1.97 million $\mathrm{m}^{3}$. M-K test $(-2.37)$ indicated the decreasing

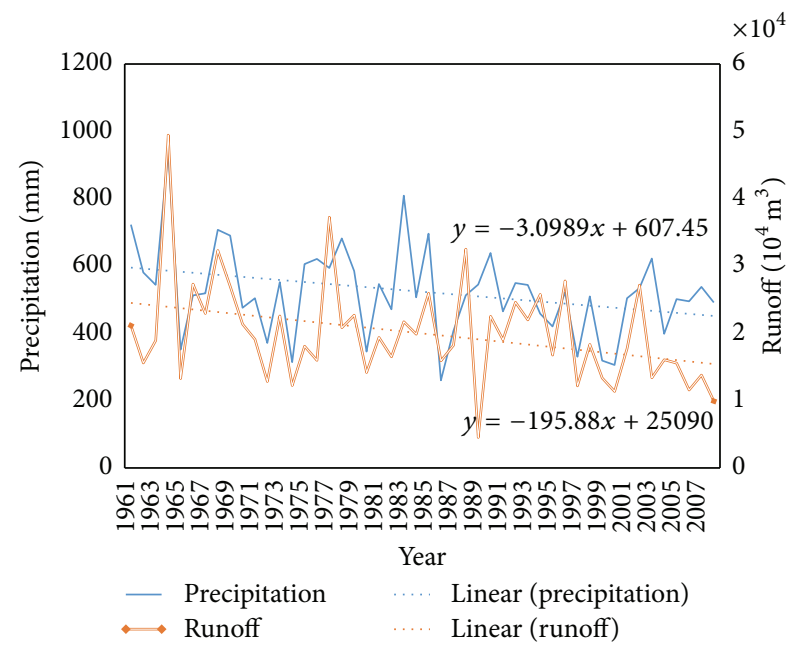

FIGURE 3: Annual precipitation and runoff in the Yanhe River during 1961-2008.

trend is significant within $99 \%$ confidence and annual runoff trend in Sen's slope estimator statistic test detected that it was reducing at the rate of 1.73 million $\mathrm{m}^{3}$ per year.

Figure 4 performed the interannual monthly average variable characters of precipitation, runoff, and sediment discharge. The amount of precipitation was basically concentrated on flood season which accounted for $71.8 \%$ of a year. Most of sediment discharge also occurred in flood season which accounted for $98.6 \%$. The distribution of monthly runoff performed the similar distribution of sediment discharge that there was $64.1 \%$ runoff occurring in flood season. 
TABLE 3: Cumulative area and ratios of human measures in Yanhe River [37].

\begin{tabular}{lcccccccccc}
\hline \multirow{2}{*}{ Year } & \multicolumn{2}{c}{ Terrace } & \multicolumn{2}{c}{ Silting dam } & \multicolumn{2}{c}{ Afforestation } & \multicolumn{2}{c}{ Grass planting } & \multicolumn{2}{c}{ Total area } \\
& Area $\left(\mathrm{Km}^{2}\right)$ & Ratio & Area $\left(\mathrm{Km}^{2}\right)$ & Ratio & Area $\left(\mathrm{Km}^{2}\right)$ & Ratio & Area $\left(\mathrm{Km}^{2}\right)$ & Ratio & Area $\left(\mathrm{Km}^{2}\right)$ & Total ratio \\
\hline 1959 & 4.13 & 8 & 4.62 & 9 & 41.33 & 82 & 0.33 & 1 & 50.41 & 0.7 \\
1969 & 47.2 & 21 & 15.83 & 7 & 161.27 & 71 & 3.73 & 2 & 228.03 \\
1979 & 97.53 & 23 & 28.73 & 7 & 286.93 & 67 & 17.47 & 4 & 430.66 & 5.7 \\
1989 & 174.33 & 15 & 37.8 & 3 & 840.73 & 70 & 145.2 & 12 & 1198.06 & 15.8 \\
1996 & 275.6 & 16 & 41.67 & 2 & 1100.2 & 66 & 259.87 & 15 & 1677.34 & 22.1 \\
2000 & 219.6 & 14 & 38.1 & 3 & 1637.5 & 67 & 180.4 & 16 & 2577.4 & 34 \\
2005 & 285.5 & 9 & 49.5 & 5 & 2128.8 & 68 & 243.5 & 18 & 3350.6 & 44.1 \\
\hline
\end{tabular}

Ratio indicates the ratio of the area in each period and total measured area. Total ratio indicates the ratio of the total measured area and total area of watershed.
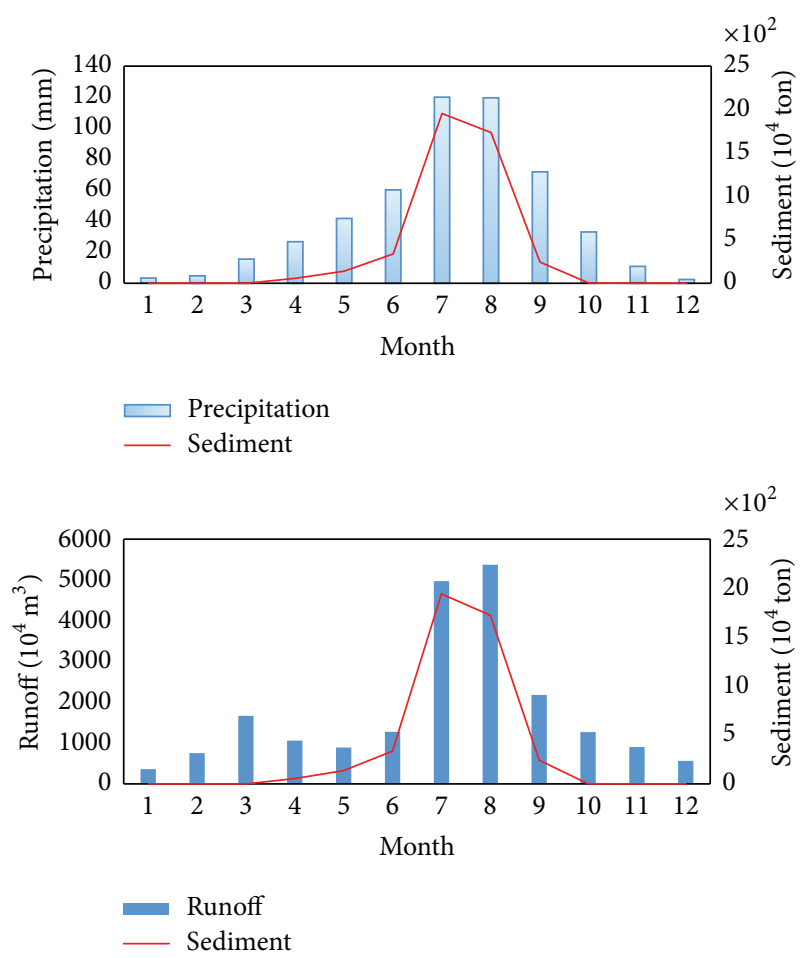

FIGURE 4: The monthly distribution of precipitation, runoff, and sediment discharge in the Yanhe River from 1961 to 2008.

There was a peak of runoff in March which was different with sediment discharge because snow melting in spring causes the rise of runoff. Another phenomenon in Figure 4 was shown that the month of maximum runoff that occurred was not in accord with the time of maximum sediment discharge that occurred. It could be explained that early intensive runoff and precipitation in July had eroded erosive soil particles on watercourse and slope and scoured them out of the outlet. Although the precipitation or runoff was larger than that in later month, the rest of erodible particles were smaller than those eroded in early time so that average sediment discharge in August had reduced. The trends of annual sediment discharge were shown in Figure 5. Sen's slope estimator test performed downward trend and sediment discharge reduced at rate of $57.24 \mathrm{t} / \mathrm{a}$. In M-K statistic test, the trend of

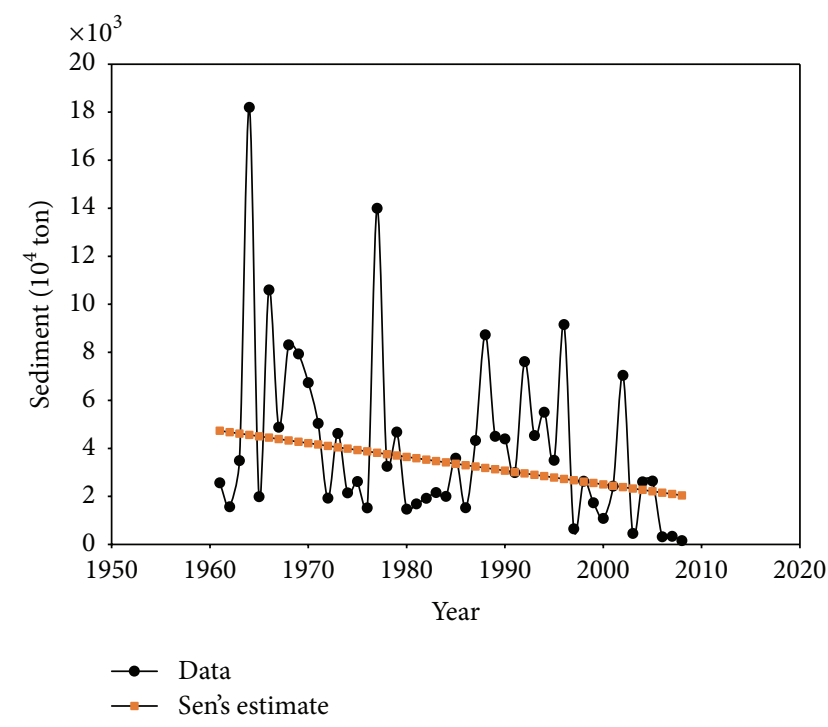

FIGURE 5: The annual sediment discharge at the Gan Guyi station from 1961 to 2008.

sediment discharge had significant reduction $(-2.37)$ within 99\% confidence level.

4.2. The Determination of Reference Period and Changing Periodicity. The reference period is defined as the fact that hydrological features and underlying surface in this period are under "nature" background (ignoring human intervention). As mentioned above, the measures of water and soil conservation in Yanhe River had been conducted since 1960s and benefits of these measures appeared around 1971 [14, 26]. Before 1959, the treated area was only $0.7 \%$ (Table 3 ). During $1959-1969,3 \%$ of total area of watershed had been treated which means the effects of humans on underlying surface were negligible. The abrupt changes of runoff and sediment discharge by Mann-Kendall test were shown in Figures 6 and 7. The trend of both runoff and sediment discharge increased before 1971. However, it was going down after 1971. This trend is in accord with the previous results that benefits had appeared around 1971. Therefore, it is reasonable to define reference period during 1961-1970.

The period during 1971-1994 is the period that increased anthropogenic intervention over Yanhe River. During this 


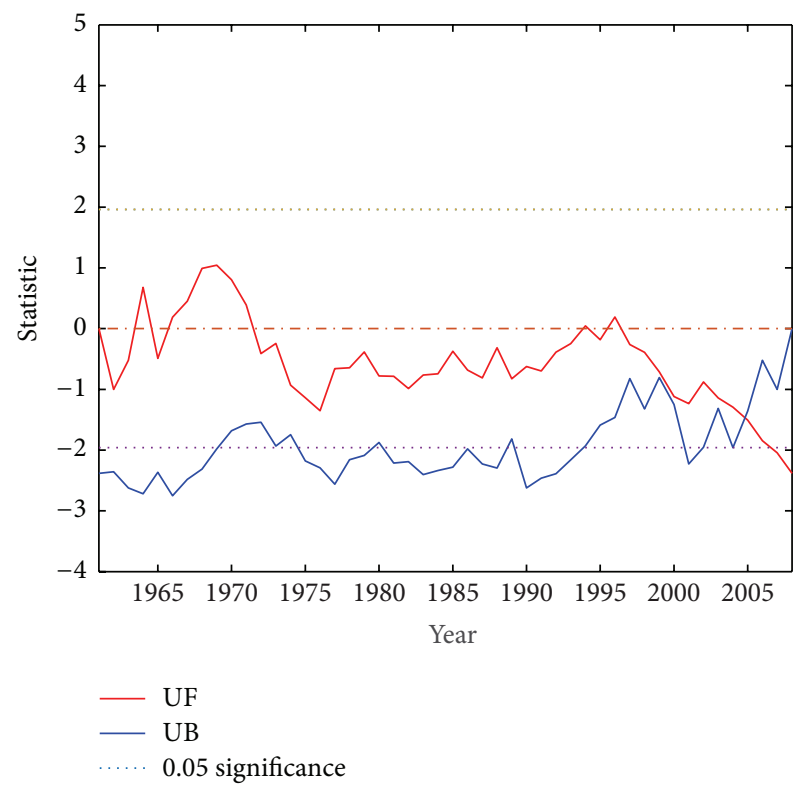

FIGURE 6: Mann-Kendall abrupt change point detection of the runoff.

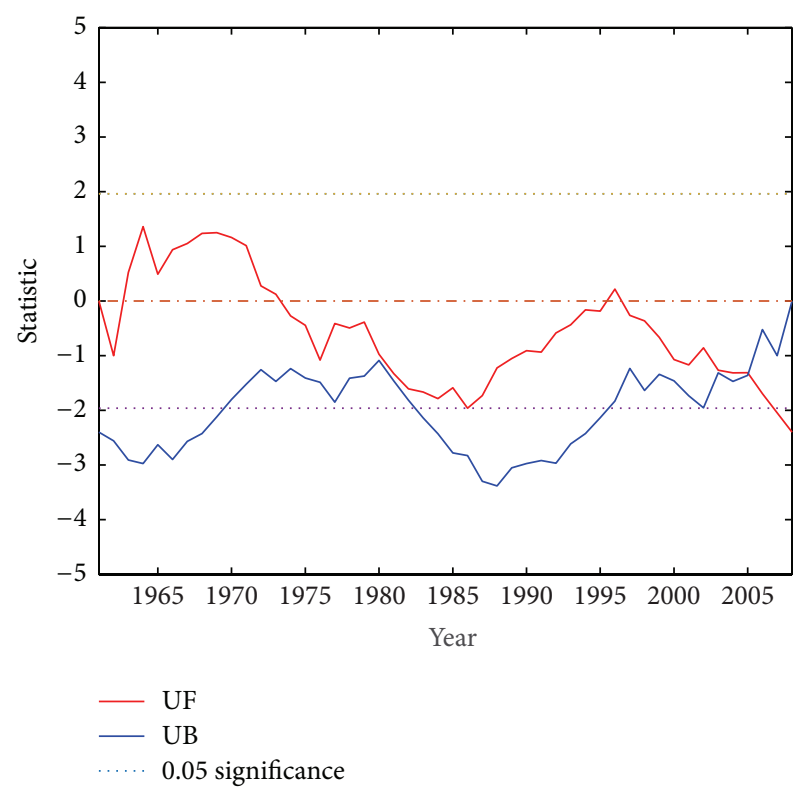

FIgURE 7: Mann-Kendall abrupt change point detection of the sediment discharge.

period, the UF of runoff and sediment discharge decreased until late 1980s and then increased. Continual water and soil conservation measures are the reason that the trend of runoff and sediment discharge decreased. There was $12.8 \%$ of Yanhe River watershed that had been treated (Table 3) during 1969-1989 and 6.3\% of watershed treatment had been completed during 1990-1996. Although there was 6.3\% increment treated, the trend of runoff and sediment discharge still upsurges in last 6 years of the period. In Figure 3, the annual precipitation during 1990-1996 increased. There were several reasons that might lead to this. One might be that water conservancy facilities such as terrace and silting dams gradually lose their function because of intensive rainfall or being out of repair. Another one could be the implement of Contracted Farmland policy during 1980s. This policy encouraged farmers in cultivating steep slope, deforesting for farmland, and mining.

There were two events that occurred during 1994-2008. One is the project of soil and water conservation in Yanhe River loaned by The World Bank (1994-2001). Another is Grain for Green project proposed by Chinese State Council in late 1990s. During 1994-2008, the runoff and sediment discharge had dramatically decreased (Figures 6 and 7). Kang et al. [38] quantified the benefits of the project of soil and water conservation in Loess Plateau and indicated that there was $549.7 \mathrm{~km}^{2}$ area replaced by vegetation. Xie et al. [39] indicated that the area of farmland decreased from $3083.56 \mathrm{~km}^{2}$ to $2191.86 \mathrm{~km}^{2}$, and the area of forest and grass increased from $4549.78 \mathrm{~km}^{2}$ to $5439.97 \mathrm{~km}^{2}$ during $1997-$ 2000. The third period during 1994-2008 is the period in which intensive anthropogenic activities were implemented in Yanhe River. The runoff and sediment discharge have their abrupt change points during this period. The abrupt change point of runoff occurred at 2005 and the abrupt change points of sediment discharge occurred at 2003 and 2005. These abrupt change points indicated that the benefits of the projects of water and soil conservation had significantly appeared around 2005.

4.3. The Effects of Climate and Anthropogenic Activities on Hydrologic Features. Runoff and sediment discharge changes were both affected by climate change and human activities. To better understand dominant factor in variation of runoff and sediment, and effects of human activities on runoff and sediment, it is necessary to quantify the effects of precipitation and human factor on runoff and sediment. The double mass curves of runoff-precipitation and sediment dischargeprecipitation in different period were shown in Figures 8 and 9. The double mass curve of runoff-precipitation in reference period showed the high correlation between runoff and precipitation. The curve should be a straight line in other periods if there were no effects of precipitation and human activity. However, the curve in other periods was not totally consistent with reference period. Therefore, it is necessary to quantify the contribution of either precipitation or anthropogenic effects to runoff and sediment discharge variation. Predicted values in period of 1971-1994 and 19952008 could be obtained by using linear regression formula of reference period which represent values under stationary underlying surface. Through the comparison of observed values and predicted values, the quantification of effects of climate and human on hydrologic features was summarized in Table 4. Actual annual average values of runoff during 1971-1994 reduced by 48 million $\mathrm{m}^{3}$ compared to reference period. The effects of precipitation accounted for $33.3 \%$ and human activities accounted for $66.7 \%$. Actual annual average values of runoff reduced by 90 million $\mathrm{m}^{3}$ during 1995-2008 compared to reference period. The effects of precipitation 


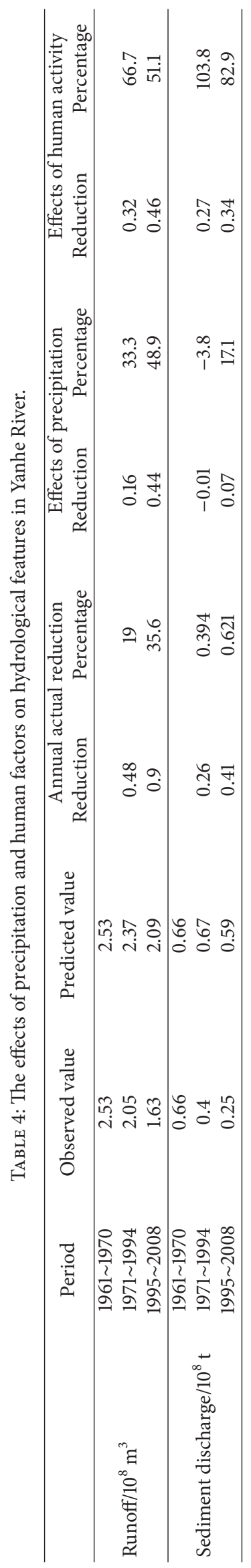




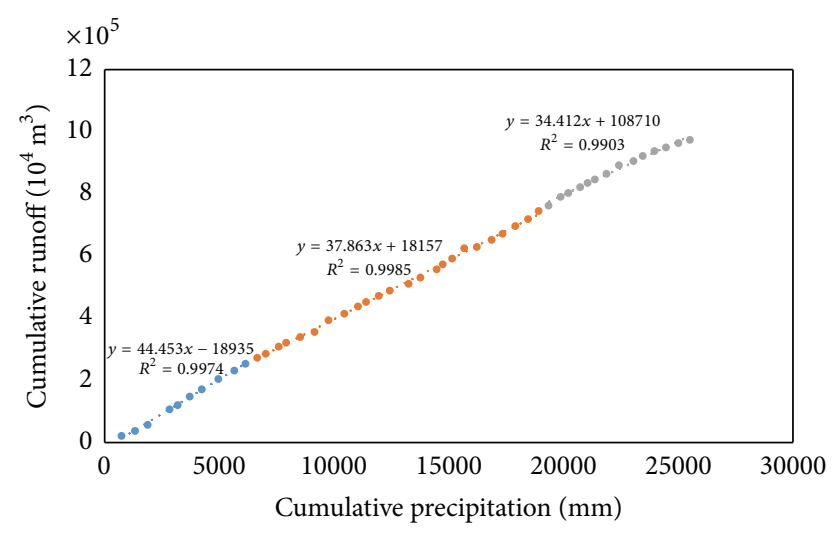

FIGURE 8: The double mass curve of the precipitation-runoff in Yanhe River.

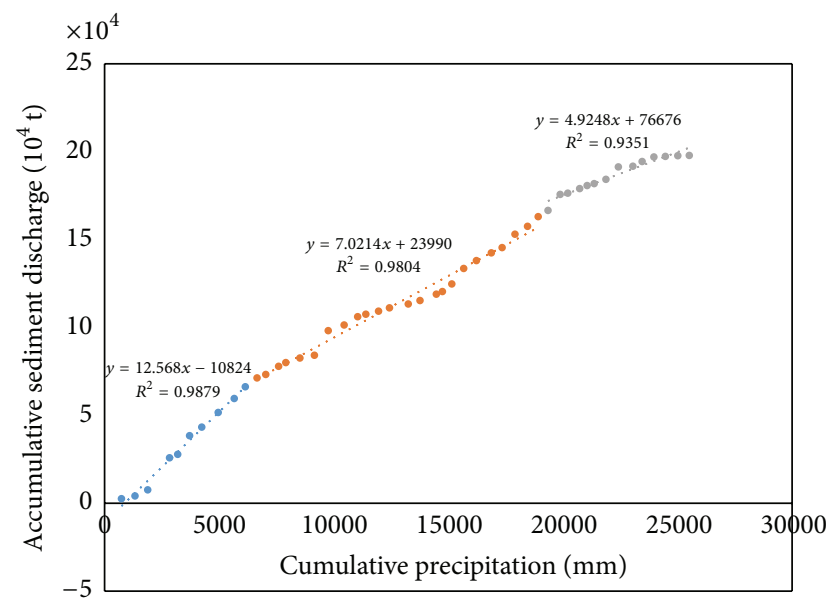

FIGURE 9: The double mass curve of the precipitation-sediment in Yanhe River.

accounted for $48.9 \%$ and human activities accounted for $51.1 \%$. For variation of sediment discharge, human activity is a major factor of reduction. The main reason might be the engineered transformation on underlying surface such as Grain for Green project. During 1971-1994, human activities had contributed $103.8 \%$ to sediment reduction. They also contributed $82.9 \%$ during $1995-2008$.

Since Grain for Green projects were conducted after 1998 that improved ability of soil and water storage for grass and forest, the contribution of anthropogenic factors to runoff reduction has reduced. However, excessive demand of increasing population and development of economy for water resource would be a challenge for runoff decline. Facility agriculture and fruit industry become major agricultural production models which acquire more water resource than traditional agriculture. In addition, runoff reduction would aggravate degeneration of natural vegetation and expansion of desertification. Therefore, quantification of effects of human factors on runoff would help improve water resource management for maintaining hydroecological positive cycle. The results of quantification for effects of human activities on sediment discharge indicate that water and soil conservation measures have achieved significant benefits.

\section{Conclusion}

The monthly distribution of precipitation, runoff, and sediment discharge was extremely uneven. $78.1 \%$ of precipitation, $64.1 \%$ of runoff, and $98.6 \%$ of sediment discharge occurred in the flood season. Precipitation, runoff, and sediment discharge performed downward trends during 1961-2008. The Mann-Kendall and Sen's slope estimator test showed that precipitation had decreased trend in seasonal distribution except winter; particularly, precipitation in fall had significantly decreased. Runoff during 1961-2008 performed significantly downward trends in summer and fall and upward trend in winter. Based on previous studies and major anthropogenic events, the periods were divided into three parts. 19611970 was set as reference period which was considered that underlying surface of watershed kept relatively stationary. The effects of precipitation and anthropogenic factors during 1971-1994 and 1995-2008 were quantified through comparing with reference period. Thereinto, anthropogenic factors contributed $66.7 \%$ and $51.1 \%$ to sediment discharge reduction during 1971-1994 and 1995-2008, respectively. They contributed $103.8 \%$ and $82.9 \%$ to runoff reduction during these two periods, respectively. The abrupt change points of runoff and sediment discharge appeared around 2005. This indicates that benefits of Grain for Green projects were significantly achieved.

The selection of reference period is important since it would affect the results in quantification of other factors. Therefore, combination with previous studies in Yanhe River would improve the accuracy for reference period selection. In addition, effects on hydrologic features are complicated. Other meteorological elements such as temperature in this paper were not considered which might impact the accuracy of evaluating effects of meteorological and human activity on the hydrologic elements. Coupling more related factors in studying climate hydrology and anthropogenic effects at watershed scale is further goal in the research.

\section{Conflict of Interests}

The authors declare that there is no conflict of interests regarding the publication of this paper.

\section{Acknowledgment}

The authors acknowledge with gratitude the research grants kindly provided by the Hundred-talent Project of the Chinese Academy of Sciences (20110009, Dr. Hongming He), the Key Research Program of Chinese Academy of Sciences (KZZDEW-04), Innovation Frontier Project of Institute of Soil and Water Conservation of the Chinese Academy of Sciences, and State Key Laboratory of Soil Erosion and Dryland Farming on the Loess Plateau (10501-192). 


\section{References}

[1] IPCC, Climate Change 2007: Synthesis Report. Contribution of Working Groups I, II and III to the Fourth Assessment Report of the Intergovernmental Panel on Climate Change, Cambridge University Press, Cambridge, UK, 2007.

[2] J. R. Goode, C. H. Luce, and J. M. Buffington, "Enhanced sediment delivery in a changing climate in semi-arid mountain basins: implications for water resource management and aquatic habitat in the northern Rocky Mountains," Geomorphology, vol. 139-140, pp. 1-15, 2012.

[3] G. Mouri, V. Golosov, S. Chalov et al., "Assessment of potential suspended sediment yield in Japan in the 21st century with reference to the general circulation model climate change scenarios," Global and Planetary Change, vol. 102, pp. 1-9, 2013.

[4] Q. Liu, Z. Yang, and B. Cui, "Spatial and temporal variability of annual precipitation during 1961-2006 in Yellow River Basin, China," Journal of Hydrology, vol. 361, no. 3-4, pp. 330-338, 2008.

[5] H. Wang, Z. Yang, Y. Saito, J. P. Liu, and X. Sun, "Interannual and seasonal variation of the Huanghe (Yellow River) water discharge over the past 50 years: connections to impacts from ENSO events and dams," Global and Planetary Change, vol. 50, no. 3-4, pp. 212-225, 2006.

[6] T. Jiang, T. Fischer, and X. X. Lu, "Larger Asian rivers: climate change, river flow, and watershed management," Quaternary International, vol. 226, no. 1, pp. 1-3, 2010.

[7] P. C. D. Milly, K. A. Dunne, and A. V. Vecchia, "Global pattern of trends in streamflow and water availability in a changing climate," Nature, vol. 438, no. 7066, pp. 347-350, 2005.

[8] Y. Wang, Y. J. Ding, B. S. Ye, F. J. Liu, J. Wang, and J. Wang, "Contributions of climate and human activities to changes in runoff of the Yellow and Yangtze rivers from 1950 to 2008," Science China Earth Sciences, vol. 56, no. 8, pp. 1398-1412, 2013.

[9] Z. Li, W. Z. Liu, F. L. Deng et al., "Effects of climate change and human activities on runoff in loess region," Journal of Ecology, vol. 30, no. 9, pp. 2379-2386, 2010 (Chinese).

[10] C. M. Liu and X. C. Zhang, "Genetic analysis of decreasing water flow in mainstream of the Yellow River," Journal of Geography, vol. 59, no. 3, pp. 323-330, 2004 (Chinese).

[11] Y. Zhang, D. Guan, C. Jin, A. Wang, J. Wu, and F. Yuan, "Analysis of impacts of climate variability and human activity on streamflow for a river basin in northeast China," Journal of Hydrology, vol. 410, no. 3-4, pp. 239-247, 2011.

[12] Z. Ma, S. Kang, L. Zhang, L. Tong, and X. Su, "Analysis of impacts of climate variability and human activity on streamflow for a river basin in arid region of northwest China," Journal of Hydrology, vol. 352, no. 3-4, pp. 239-249, 2008.

[13] P. C. D. Milly, J. Betancourt, M. Falkenmark et al., "Climate change-stationarity is dead: whither water management?" Science, vol. 319, no. 5863, pp. 573-574, 2008.

[14] X. Mu, C. Basang, Z. Lu, P. Gao, F. Wang, and X. Zhang, "Impact of soil conservation measures on runoff and sediment in Hekou-Longmen region of the Yellow River," Journal of Sediment Research, no. 2, pp. 36-41, 2007 (Chinese).

[15] X. Mu, L. Zhang, T. R. McVicar, B. Chille, and P. Gau, "Analysis of the impact of conservation measures on stream flow regime in catchments of the Loess Plateau, China," Hydrological Processes, vol. 21, no. 16, pp. 2124-2134, 2007.

[16] H. Tao, M. Gemmer, Y. G. Bai, B. D. Su, and W. Y. Mao, “Trends of streamflow in the Tarim River Basin during the past 50 years: human impact or climate change?" Journal of Hydrology, vol. 400, no. 1-2, pp. 1-9, 2011.

[17] J. Q. Zhai, B. D. Su, V. Krysanova, T. Vetter, C. Gao, and T. Jiang, "Spatial variation and trends in PDSI and SPI indices and their relation to streamflow in ten large regions of China," Journal of Climate, vol. 23, no. 3, pp. 649-663, 2010.

[18] H. He, J. Zhou, M. R. Peart, J. Chen, and Q. Zhang, "Sensitivity of hydrogeomorphological hazards in the Qinling Mountains, China," Quaternary International, vol. 282, pp. 37-47, 2012.

[19] H. He, J. Zhou, Q. Yu, Y. Q. Tian, and R. F. Chen, "Flood frequency and routing processes at a confluence of the middle Yellow River in China," River Research and Applications, vol. 23, no. 4, pp. 407-427, 2007.

[20] J. P. M. Syvitski, C. J. Vörösmarty, A. J. Kettner, and P. Green, "Impact of humans on the flux of terrestrial sediment to the global coastal ocean," Science, vol. 308, no. 5720, pp. 376-380, 2005.

[21] X. L. Yue, X. M. Mu, G. J. Zhao, H. B. Shao, and P. Gao, "Dynamic changes of sediment load in the middle reaches of the Yellow River basin, China and implications for eco-restoration," Ecological Engineering, vol. 73, pp. 64-72, 2014.

[22] G. J. Zhao, P. Tian, X. M. Mu, J. Y. Jiao, F. Wang, and P. Gao, "Quantifying the impact of climate variability and human activities on streamflow in the middle reaches of the Yellow River basin, China," Journal of Hydrology, vol. 519, pp. 387-398, 2014.

[23] G. M. Kondolf, Y. Gao, G. W. Annandale et al., "Sustainable sediment management in reservoirs and regulated rivers: Experiences from five continents," Earth's Future, vol. 2, no. 5, pp. 256-280, 2014.

[24] Q. Yan, T. Lei, C. Yuan et al., "Effects of watershed management practices on the relationships among rainfall, runoff, and sediment delivery in the hilly-gully region of the Loess Plateau in China," Geomorphology, vol. 228, pp. 735-745, 2015.

[25] Yellow River Conservancy Commission of MWR, Yellow River Sediment Bulletin, China WaterPower Press, Beijing, China, 2008 (Chinese).

[26] P. Gao, X. Zhang, X. Mu, F. Wang, R. Li, and X. Zhang, "Trend and change-point analyses of streamflow and sediment discharge in the Yellow River during 1950-2005," Hydrological Sciences Journal, vol. 55, no. 2, pp. 275-285, 2010 (Chinese).

[27] H. Xie, R. Lee, Q. Yang et al., "Effect of returning farmland to forest (pasture) and changes of precipitation on soil erosion in the Yanhe Basin," Scientia Agricultura Sinica, no. 2, pp. 569-576, 2009.

[28] Z. Lian, P. Liu, C. Chen et al., "Effects of sediment reduction by restoration on the loess plateau," Bulletin of Soil and Water Conservation, vol. 1, pp. 10-13, 2008 (Chinese).

[29] X. He, Y. Gao, and Z. Zhu, "The simulation of spontaneous restoration of vegetation spatial pattern in the Yanhe River Catchment," in Proceedings of the 4th International Yellow River Forum on Ecological Civilization and River Ethics, vol. 2, pp. 148155, Zhengzhou, China, 2010.

[30] L. Qiu, Evaluation of Impacts of the Climatic Variable Changes and Human Activity on the Runoff and Sediment in the Yanhe Watershed, Northwest A \& F University, Yangling, China, 2012.

[31] Z. Zhou, The Coupling Analysis of Landscape Pattern and Hydrological Process in Yanhe Watershed, Shaanxi Normal University, Xi’an, China, 2014.

[32] H. B. Mann, "Nonparametric tests against trend," Econometrica, vol. 13, no. 3, pp. 245-259, 1945. 
[33] P. K. Sen, "Estimates of the regression coefficient based on Kendall's tau," Journal of the American Statistical Association, vol. 63, no. 324, pp. 1379-1389, 1968.

[34] D. A. Burns, J. Klaus, and M. R. McHale, "Recent climate trends and implications for water resources in the Catskill Mountain region, New York, USA," Journal of Hydrology, vol. 336, no. 1-2, pp. 155-170, 2007.

[35] X. Mu, X. Zhang, P. Gao et al., "Theory of double mass curves and its applications in hydrology and meteorology," Journal of China Hydrology, vol. 30, no. 4, pp. 47-51, 2010 (Chinese).

[36] X. M. Mu, X. Q. Zhang, P. Gao, and F. Wang, "Theory of double mass curves and its applications in hydrology and meteorology," Journal of China Hydrology, vol. 30, no. 4, pp. 47-51, 2010 (Chinese).

[37] C. Lee, H. Wang, F. Yu et al., "Impact of soil and water conservation on runoff and sediment in Yanhe River Basin," Science of Soil and Water Conservation, no. 1, pp. 1-8, 2011 (Chinese).

[38] L. Kang, Y. Wei, Y. Wang, and W. Yao, "Preliminary opinions on ecological benefits of eco-environment construction of soil and water conservation on Loess Plateau," Chinese Journal of EcoAgriculture, vol. 12, no. 4, pp. 198-200, 2004 (Chinese).

[39] H. Xie, R. Li, Q. Yang, J. Li, and W. Liang, "Effect of returning farmland to forest (pasture) and changes of precipitation on soil erosion in the yanhe basin," Journal of Scientia Agricultra Sinica, vol. 42, no. 2, pp. 569-579, 2009 (Chinese). 

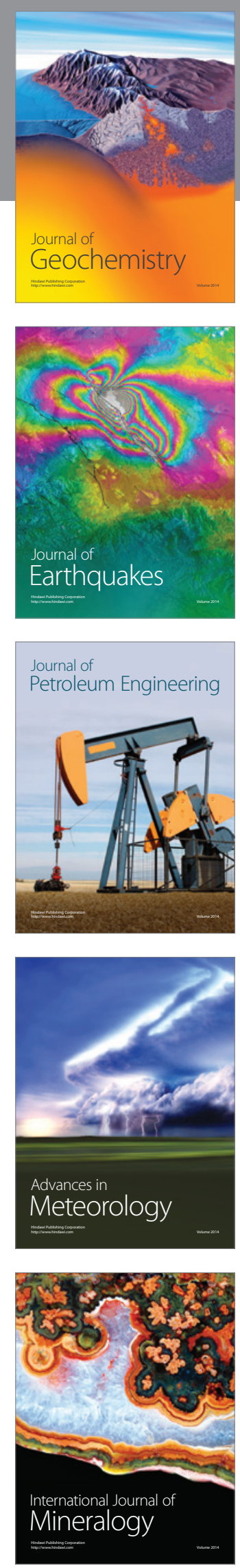
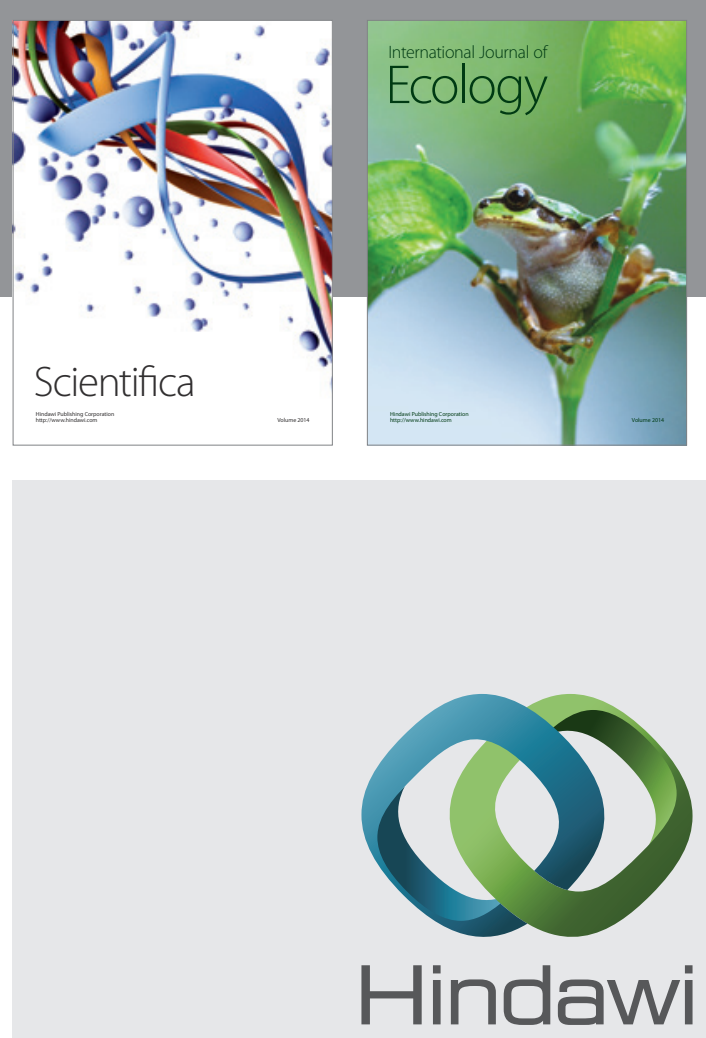

Submit your manuscripts at

http://www.hindawi.com
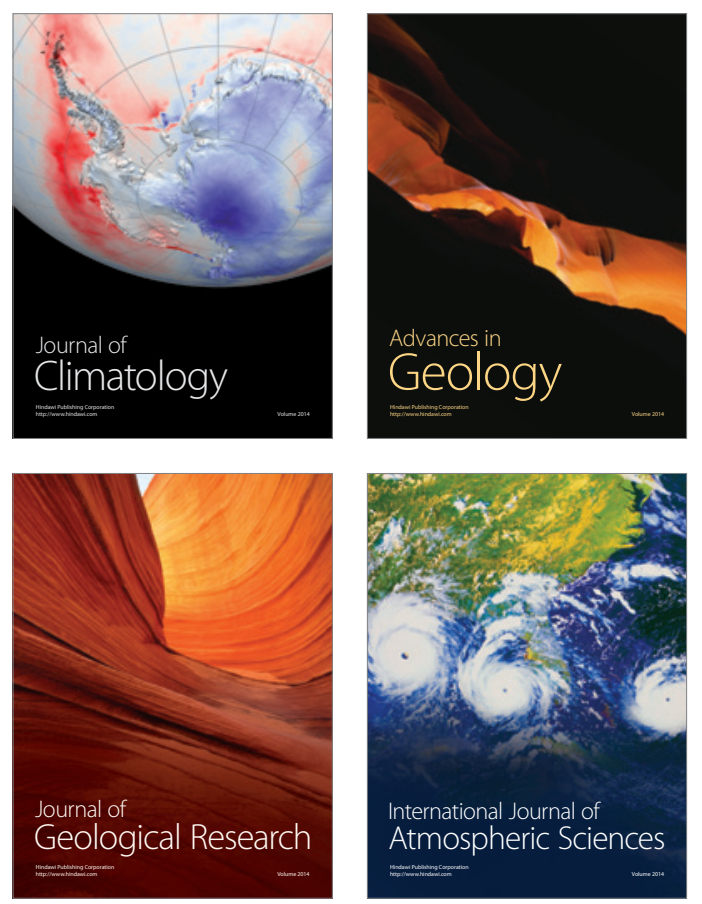

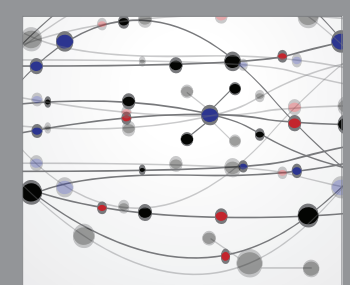

The Scientific

\section{World Journal}
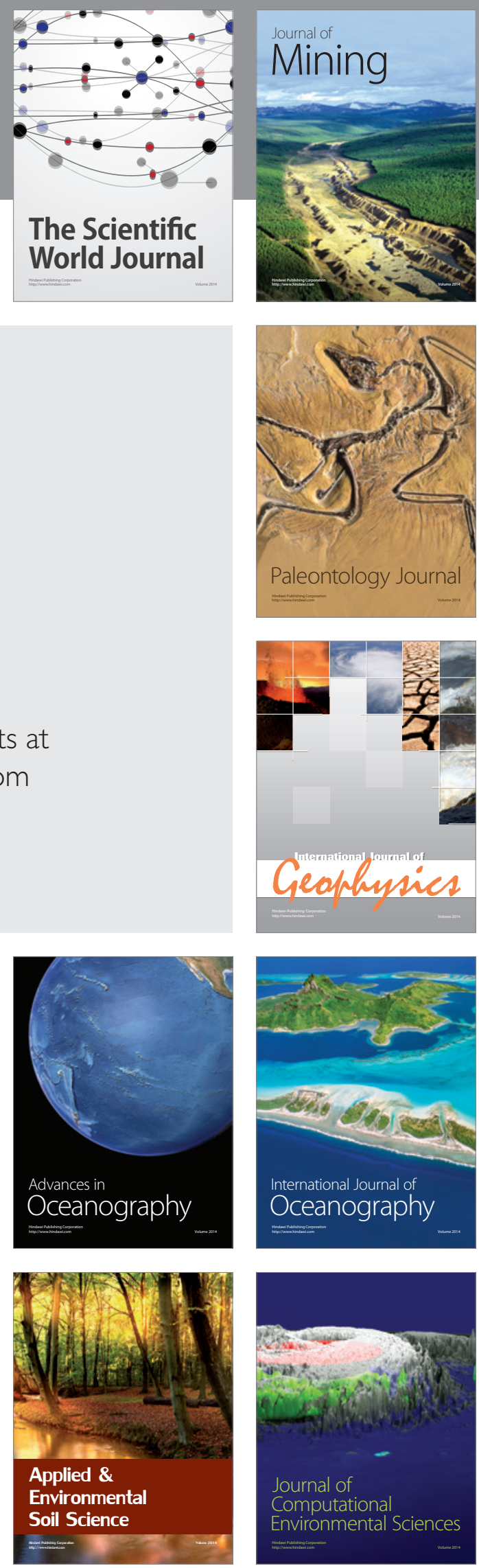